\title{
HEURÍSTICAS NO DESENVOLVIMENTO DE PRODUTOS: IDENTIFICAÇÃO E ANÁLISE A PARTIR DE EMPREENDIMENTOS DIGITAIS
}

Jéssica Ferreira dos Santos (jessicafsanntos@gmail.com) - Pontifícia Universidade Católica de Minas Gerais (PUC-Minas).

Marianna Barros Badaró (marianna.badaro@hotmail.com) - Pontifícia Universidade Católica de Minas Gerais (PUC-Minas).

Sarah Dourado Guimarães (sarah.dguimaraes@gmail.com) - Pontifícia Universidade Católica de Minas Gerais (PUC-Minas).

Matheus Luiz Pontelo de Souza (mslzposa@gmail.com) - Pontifícia Universidade Católica de Minas Gerais (PUC-Minas).

\section{RESUMO}

$\mathrm{O}$ ambiente de desenvolvimento de produtos, especialmente no contexto do empreendedorismo digital, é repleto de incertezas e mudanças, tornando a tomada de decisão um desafio considerável. Devido a isto, é comum a busca por modelos analíticos enquanto condição necessária para gerar melhores resultados. Há indícios, contudo, de que heurísticas superam tais modelos tanto em simplicidade quanto em precisão. Portanto, este estudo tem como objetivo identificar heurísticas adaptadas ao desenvolvimento de produtos em empreendimentos digitais, bem como uma validação de tais heurísticas por empreendedores da área. Utilizando uma abordagem de multi-métodos - análise de template apoiada por princípios de grounded theory, o estudo obteve uma lista de heurísticas priorizada pela relevância atribuída pelos empreendedores, além de reflexões sobre o potencial e limitações dessas heurísticas no contexto em questão.

Palavras-chave: Heurísticas; Desenvolvimento de produto; Empreendedorismo digital; Racionalidade ecológica; Incerteza. 


\section{INTRODUÇÃO}

No contexto do empreendedorismo digital (ED), o processo de desenvolvimento de um produto - ou solução - é fundamental (RATINHO; HARMS; WALSH, 2015). O ambiente de desenvolvimento de produtos (DP), especialmente no contexto do ED, é repleto de incertezas e mudanças. O que torna a tomada de decisão um desafio considerável, ainda mais sob severas restrições de tempo e informação, fatores que evidenciam a necessidade de abordagens de suporte que conciliem precisão e simplicidade.

Ao se deparar com desafios semelhantes, é comum a busca por modelos analíticos ou matemático-racionais enquanto condição necessária para gerar melhores resultados. Este caminho, contudo, apresenta limitações graves em contextos complexos, incertos e mutáveis (ARTINGER et al., 2015; SULL; EISENHARDT, 2012; BETTIS, 2017). Neste contexto, Bettis (2017) demonstra a impossibilidade de usar modelos matemático-racionais, dado que requerem um tempo impraticável entre consolidar informações, realizar análise, julgamento e atingir uma conclusão logicamente justificável. Sull e Eisenhardt (2015) endossam a crítica a essa "racionalidade pura", e sugerem que se deve buscar soluções simples para problemas complexos, e não o contrário, como é o padrão de comportamento em ambientes complexos.

Uma alternativa à lógica analítico-racional para a tomada de decisão são modelos mais simples, denominados heurísticas (ARTINGER et al., 2015; LUAN; REB; GIGERENZER, 2019; SULL; EISENHARDT, 2012). Segundo Bettis (2017), heurísticas são critérios para decidir um curso de ação mais eficaz dentre vários possíveis, conciliando simplicidade e precisão. Eisenhardt e colegas denominam as heurísticas regras simples (RS), capazes de orientar a decisão (SULL; EISENHARDT, 2015; BINGHAM; EISENHARDT, 2011).

Literatura recente indica que o uso de heurísticas em condições de incerteza e mudança frequente apresenta desempenho igual ou melhor do que modelos analíticos tanto em uma perspectiva geral (ARTINGER et al., 2015; BETTIS, 2017; LUAN; REB; GIGERENZER, 2019; SULL; EISENHARDT, 2012) quanto com foco específico no desenvolvimento de produtos (WEST; ACAR; CARUANA, 2020). Assim, seu estudo e aplicação traz oportunidades de auxílio à área de DP em ambientes complexos, incertos e mutáveis.

Entretanto, percebe-se carência de pesquisas empíricas sobre o tema (STINGL; GERALDI, 2021; WENZEL; STJERNE, 2021). Tal carência é ainda maior em termos de estudos com 
foco em DP que busquem oferecer uma lista de heurísticas e orientação para os praticantes da área - como é o caso deste artigo.

Portanto, o objetivo deste estudo é oferecer uma lista de heurísticas adaptadas ao desenvolvimento de produtos em empreendimentos digitais, bem como uma validação de tais heurísticas por empreendedores da área. Utilizando uma combinação de análise de template com princípios de grounded theory, o estudo obteve uma lista de heurísticas priorizada pela relevância atribuída pelos empreendedores, além de reflexões sobre seu potencial e limitações no contexto em questão.

\section{REFERENCIAL TEÓRICO}

O empreendedorismo digital (ED) trata da digitalização - parcial ou total - do que seria físico em um ambiente analógico (HULL et al., 2007). Para Zaheer, Breyer, Dumay (2019), o ED pode ser definido como o processo de criar uma startup digital. Ries (2011), por sua vez, define uma startup como uma instituição cujo objetivo é criar produtos ou serviços sob condições de extrema incerteza.

O ED e o desenvolvimento de produto requerem decisões e ações precisas e rápidas em um ambiente geralmente complexo, ambíguo e mutável. Herbert Simon, em suas pesquisas sobre o comportamento humano e decisões em ambientes semelhantes, foi pioneiro no estudo de heurísticas. Especialmente a partir do conceito de racionalidade limitada (SIMON, 1982), segundo o qual o agente tomador de decisão não possui tempo e capacidade cognitiva suficientes para coletar dados e analisar todas as alternativas para uma tomada de decisão ótima, dada a complexidade do sistema em que está inserido (SIMON, 1955). A partir de Simon, estruturou-se a linha de estudos em torno de heurísticas e vieses, contendo tanto perspectivas a favor do potencial de heurísticas em tais ambientes (como é o foco predominante deste estudo), quanto perspectivas críticas, especialmente a partir dos estudos de Tversky e Kahneman (ex.: TVERSKY; KAHNEMAN, 1974). Detalhes sobre tal trajetória desde Simon, bem como sobre as possibilidades e desafios da definição e estudo de heurísticas encontram-se na literatura (ex.: GRIFFIN et al, 2013; ZHANG; CUETO, 2015). Este estudo, por sua vez, aborda de modo simplificado a definição de heurísticas para, então, se voltar para o apoio à decisão e ação de empreendedores digitais. É utilizada a definição proposta por Bettis (2017, p. 2632), para quem heurísticas são:

“critérios, métodos ou princípios para decidir, dentre diversos cursos alternativos, qual promete ser mais efetivo para alcançar um objetivo qualquer. Elas representam 
um compromisso entre dois requisitos: a necessidade de fazer tais critérios simples $e$, ao mesmo tempo, o desejo de vê-los separar corretamente as decisões boas das ruins".

De modo adicional, será utilizada a lente de heurísticas entendidas como RS (ex.: BINGHAM; EISENHARDT, 2011; DAVIS; EISENHARDT, 2009; SULL; EISENHARDT, 2012, 2015). Para tais autores, RS simplificam as informações ao buscar soluções rápidas com menor esforço.

Segundo Sull e Eisenhardt (2012), RS apoiam a priorização dentre várias alternativas em ambientes de muita incerteza. Já Artinger et al., (2015) demonstram que RS podem levar a decisões mais rápidas e precisas do que algoritmos complexos, especialmente em contextos de incerteza, instabilidade ou amostras pequenas de dados. Luan, Reb e Gigerenzer (2019) corroboram Artinger et al., (2015), demonstrando com maior robustez tais argumentos em favor das heurísticas.

Um exemplo de aplicação de RS é exposto por Sull e Eisenhardt (2012): em uma companhia brasileira, com poucos recursos financeiros para inovação, os autores observaram bons resultados pela adoção de quatro RS: 1) remover obstáculos para aumento da receita; 2) minimizar despesas iniciais; 3) oferecer benefícios no curto prazo; 4) reutilizar recursos existentes.

Outro exemplo de RS é exposto por Sull e Eisenhardt (2015, p. 68): “ao contratar, misture nerds de Harvard com improvisadores de Chicago e depois balance". Em outro contexto, de desenvolvimento de uma nova solução de pagamentos, foram utilizadas RS baseadas para selecionar dentre possíveis soluções: 1) é possível concluir o pagamento em menos de cinco passos? 2) Houve mais de uma solicitação na mesma forma de pagamento? (SULL; EISENHARDT, 2015).

Finalmente, deve-se notar que RS devem se adequar aos ambientes, não sendo universais (SULL; EISENHARDT, 2012). Em consonância com o princípio da racionalidade ecológica (ARTINGER et al., 2015), segundo o qual deve-se sempre julgar a adaptabilidade de uma heurística ao ambiente em questão (LUAN; REB; GERENZER, 2019). Em outras palavras, deve-se tratar heurísticas não como ferramentas para todos os fins, mas princípios com bom desempenho em ambientes específicos (ARTINGER et al, 2015), eliminando heurísticas inadequadas para decisões específicas (BETTIS, 2017) e evitando o que a literatura denomina risco de abordagens one-size-fits-all (SALERNO et al., 2015). 


\section{METODOLOGIA}

Este artigo utilizou uma abordagem predominantemente qualitativa-exploratória, tendo por base a análise de template (KING; BROOKS, 2017). Para o tratamento de dados, foram utilizadas considerações provenientes de Gioia et al (2013), que conjuga princípios de grounded theory em consonância com a análise de template. A Figura 1 evidencia os passos adotados pela pesquisa.

FIGURA 1 - Fluxo de pesquisa.

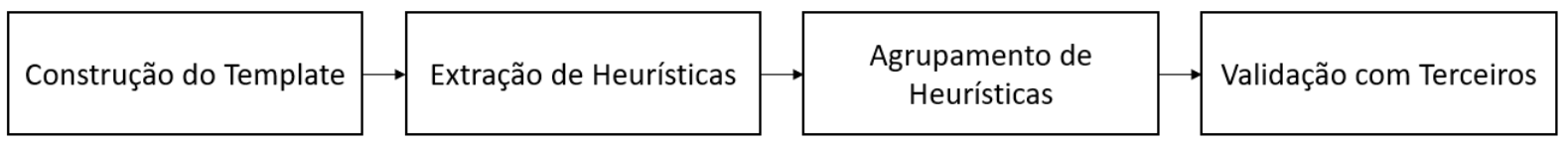

Fonte: Autores

As etapas propostas por King e Brooks (2017, p. 2-225 a 2-227) foram seguidas em consonância com a Figura 1. Primeiro, para construir o template, tornar-se familiar com os dados analisados e realizar uma codificação preliminar (KING; BROOKS, 2017), o que foi feito pelo pesquisador responsável pela construção do template.

Em seguida, o template foi submetido a três etapas de validação para cumprir os passos modificar/desenvolver o template e obter uma versão final, propostos por King e Brooks (2017): a primeira, indutiva, a partir do agrupamento do resultado da codificação inicial em temas de primeira e segunda ordem conforme Gioia et al (2013); a segunda, dedutiva, na qual o template foi confrontado com dois métodos da área do ED (BLANK; DORF, 2012; SOUZA; MELO FILHO; CHENG, 2020) e dois estudos voltados à identificação de heurísticas (MANIMALA, 1992; MAKINGS; BARNARD, 2019). Estes testes buscaram submeter o template a uma prova de robustez/abrangência; finalmente, foi realizada outra etapa de teste dedutivo que envolveu seis codificadores independentes durante dois meses, até que uma versão final do template foi obtida, conforme Figura 2. Este template foi utilizado para uma codificação ampla, no contexto de um projeto de pesquisa de doutorado. Para este artigo, contudo, apenas as classes afins ao desenvolvimento de produto foram utilizadas. 
FIGURA 2 - Template de apoio à codificação

\begin{tabular}{|c|c|c|}
\hline Nível 1 - Task Group & Nível 2 - Task & Código \\
\hline Ações sobre Recursos Humanos & Atrair/manter talentos & 1.1 \\
\hline Ações sobre Recursos Humanos & Buscar/atingir complementaridade / diversidade em recursos humanos & 1.2 \\
\hline Ações sobre Recursos Humanos & Treinar/desenvolver as capacidades/produtividade da equipe existente & 1.3 \\
\hline Ações sobre Recursos Humanos & Desenvolver/ nutrir missão, cultura e/ou valores & 1.4 \\
\hline Ações sobre Recursos Humanos & Estilo de gestão (especifico aos recursos humanos) & 1.5 \\
\hline Ações/comportamento empreendedor & Criar/ expandir capital social & 2.1 \\
\hline Ações/comportamento empreendedor & Alocar, realocar e/ou priorizar recursos & 2.2 \\
\hline Ações/comportamento empreendedor & Definir/redefinir visão do negócio & 2.3 \\
\hline Ações/comportamento empreendedor & Persistência/resiliência & 2.4 \\
\hline Ações/comportamento empreendedor & Gestão de crises (enquanto a crise está instalada) & 2.6 \\
\hline Ações/comportamento empreendedor & Mentalidade (mindset) empreendedor & 2.7 \\
\hline Ações/comportamento empreendedor & Buscar aprendizagem continua dos fundadores & 2.8 \\
\hline $\begin{array}{l}\text { Ações sobre ideias, oportunidades e/ou definição } \\
\text { do conceito da solução (proposta de valor) }\end{array}$ & Buscar ideias e/ou lapidar oportunidades & 3.1 \\
\hline $\begin{array}{c}\text { Ações sobre ideias, oportunidades e/ou definição } \\
\text { do conceito da solução (proposta de valor) }\end{array}$ & $\begin{array}{c}\text { Estudo / Análise de Mercado durante avaliação de } \\
\text { oportunidades/ideias/proposta de valor }\end{array}$ & 3.2 \\
\hline $\begin{array}{l}\text { Ações sobre ideias, oportunidades e/ou definição } \\
\text { do conceito da solução (proposta de valor) }\end{array}$ & $\begin{array}{l}\text { Coleta de feedback e/ou aproximação a clientes/pessoas para aprimorar } \\
\text { ideias, protótipos, MVPs... }\end{array}$ & 3.3 \\
\hline $\begin{array}{l}\text { Ações sobre ideias, oportunidades e/ou definição } \\
\text { do conceito da solução (proposta de valor) }\end{array}$ & $\begin{array}{l}\text { Inovar na proposta de valor e/ou criar diferenciais no produto/solução, } \\
\text { incluindo criar MVPs/protótipos }\end{array}$ & 3.4 \\
\hline $\begin{array}{l}\text { Ações sobre ideias, oportunidades e/ou definição } \\
\text { do conceito da solução (proposta de valor) }\end{array}$ & Estimular a mudança/renovação/inovação na empresa já consolidada & 3.5 \\
\hline $\begin{array}{l}\text { Suporte ao ganho de escala e/ou estruturação de } \\
\text { processos internos }\end{array}$ & Planejamento médio/longo prazo & 4.1 \\
\hline $\begin{array}{l}\text { Suporte ao ganho de escala e/ou estruturação de } \\
\text { processos internos }\end{array}$ & $\begin{array}{l}\text { Criar processos para suportar crescimento com qualidade e/ou } \\
\text { otimizar/ganho de eficiência processos existentes }\end{array}$ & 4.2 \\
\hline $\begin{array}{l}\text { Suporte ao ganho de escala e/ou estruturação de } \\
\text { processos internos }\end{array}$ & Ações juridico-contábeis & 4.3 \\
\hline $\begin{array}{l}\text { Suporte ao ganho de escala e/ou estruturação de } \\
\text { processos internos }\end{array}$ & Definir e/ou acompanhar números/indicadores/métricas & 4.4 \\
\hline $\begin{array}{l}\text { Posicionamento, entrada, difusão e/ou consolidação } \\
\text { no mercado }\end{array}$ & Dimensionar / segmentar e/ou definir mercado-alvo & 5.1 \\
\hline $\begin{array}{l}\text { Posicionamento, entrada, difusão e/ou consolidação } \\
\text { no mercado }\end{array}$ & Definir preço e/ou modelo de negócio & 5.2 \\
\hline $\begin{array}{l}\text { Posicionamento, entrada, difusão e/ou consolidação } \\
\text { no mercado }\end{array}$ & Atração / aquisição de novos clientes & 5.3 \\
\hline $\begin{array}{l}\text { Posicionamento, entrada, difusão e/ou consolidação } \\
\text { no mercado }\end{array}$ & $\begin{array}{l}\text { Fortalecimento de marca e/ou relacionamento /manutenção de clientes já } \\
\text { adquiridos }\end{array}$ & 5.4 \\
\hline Ações sobre Recursos Financeiros & Minimizar investimento inicial & 6.1 \\
\hline Ações sobre Recursos Financeiros & $\begin{array}{l}\text { Apoio à obtenção de investimento (pré-investimento) e/ou decisão sobre } \\
\text { obter investimento ou não }\end{array}$ & 6.2 \\
\hline Ações sobre Recursos Financeiros & Gestão do relacionamento com investidores (pós-investimento) & 6.3 \\
\hline Continuar ou não com o negócio & Decisões sobre continuar ou não com o negócio & 7.1 \\
\hline
\end{tabular}

Fonte: Autores

A partir do template pronto, iniciou-se a etapa de extração de heurísticas (Figura 1). A Figura 3 foi construída para detalhamento das etapas 2 e 3 da Figura 1. 
FIGURA 3 - Roteiro de definição das RS

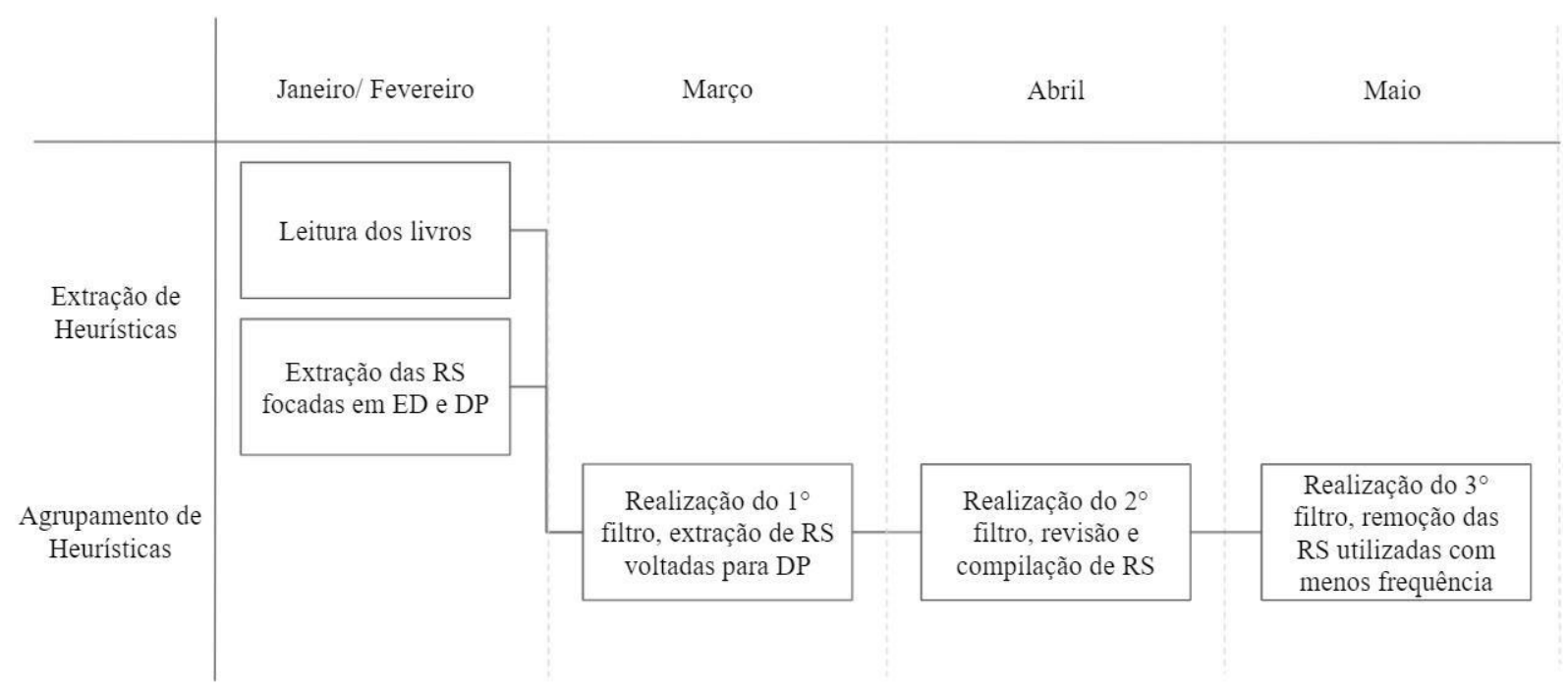

Fonte: Autores

A fonte de dados foi composta por quatro livros de startups e/ou empreendedores de sucesso, como o Airbnb e a Easy Taxi (BHARGAVA; HERMAN, 2020; GALLAGHER, 2017; GOMES, 2015; GREEN, 2017). Dado que heurísticas são elementos linguísticos geralmente construídos a partir da experiência (SULL; EISENHARDT, 2015), tal escolha foi guiada pela hipótese de que esses livros oferecem rica variedade de RS por ter foco no empreendedorismo digital e por narrar trajetórias de aprendizado de startups/empreendedores. Com efeito, após a codificação, mais de 3000 RS foram obtidas, confirmando a hipótese inicial.

Seguindo princípios de validade/confiabilidade de literatura da área (KING; BROOKS, 2017; O'CONNOR; JOFFE, 2020), a codificação foi realizada por três duplas independentes (tanto entre as duplas quanto internamente às duplas) de codificadores, sob a supervisão do pesquisador que construiu o template e treinou os codificadores. Indicadores como o $\mathrm{U}$ de Guetzkow e o Kappa de Cohen foram utilizados para tratar divergências na codificação (FRANCO; ROWETTE, 2011).

Em seguida, as RS foram filtradas (Figura 3) em pouco mais de $300 \mathrm{RS}$, a partir das categorias do template mais próximas à área de desenvolvimento de produto (ex.: análise de oportunidades/ideias/mercado, prototipagem, manutenção, estratégia, métricas/ indicadores). Tais RS foram então agrupadas de acordo com as indicações de Gioia et al (2013) em um procedimento sistemático de agrupamento e revisão até se obter uma lista de $23 \mathrm{RS}$ de segundo nível e relacionadas ao DP. Por fim, esta lista foi resumida a uma lista final de $12 \mathrm{RS}$ por meio da junção de algumas RS entre si e remoção de RS percebidas como de menor frequência na base de dados inicial de 300 RS. 
Utilizando essa lista final, a quarta etapa da metodologia teve início. Os resultados da análise de template - no caso, as RS - foram submetidos ao escrutínio de terceiros para adicionar validade à análise (KING; BROOKS, 2017). Foram escolhidos 5 entrevistados de diferentes formações e idade, todos com experiência em DP no ED (detalhes na Figura 4).

FIGURA 4 - Informações dos entrevistados

\begin{tabular}{|c|c|c|c|c|}
\hline Entrevistas & Formação & $\begin{array}{c}\text { Tempo no } \\
\text { empreendedorismo }\end{array}$ & Tempo no DP & Experiência em produtos \\
\hline 1 & $\begin{array}{c}\text { Mestre em Inovação Tecnológica e } \\
\text { Doutorado (em curso) }\end{array}$ & 6 anos & 10 anos & Físicos e Digitais \\
\hline 2 & Bacharel em Engenharia Elétrica & 2 anos & 1 ano & Digitais \\
\hline 3 & $\begin{array}{c}\text { Bacharel em Engenharia de } \\
\text { Produção }\end{array}$ & 2 anos & 21 anos & Físicos e Digitais \\
\hline 4 & Ensino Médio Completo & 35 anos & 3 anos & Físicos e Digitais \\
\hline 5 & $\begin{array}{c}\text { Graduanda em Engenharia de } \\
\text { Produção }\end{array}$ & 2 anos &
\end{tabular}

Fonte: Autores

As entrevistas semiestruturadas começaram com uma breve explicação do que são RS, seguida pela demonstração da lista de 12 RS para cada entrevistado. Em seguida, foram feitas questões como: Você já utilizou essa RS? Ajudaram/atrapalharam em alguma tomada de decisão? Quais as limitações de seu uso? Dentre outras perguntas, para fomentar o escrutínio pelos empreendedores. Os entrevistadores - que também foram codificadores - estimularam os entrevistados a oferecer exemplos da vida real dos empreendedores que justificassem suas respostas. Devido ao contexto de pandemia, as entrevistas foram realizadas remotamente. Todas foram gravadas e, em média, com a duração de 37 minutos.

\section{RESULTADOS E DISCUSSÃO}

O primeiro resultado deste trabalho foi a lista de Regras Simples, representada na Figura 5, a partir do processamento descrito no capítulo anterior. 
FIGURA 5 - Lista de Regras Simples

\begin{tabular}{|c|c|}
\hline Código & Heuristicas \\
\hline FDC & $\begin{array}{l}\text { Pense fora da caixa sobre o que o mercado e as indústrias podem ser inovados. Fazendo isso, } \\
\text { você deu o primeiro passo para lançar uma startup potencialmente bem-sucedida. }\end{array}$ \\
\hline NEC & $\begin{array}{l}\text { Venda uma "necessidade" e não um "desejo", assim, você não corre o risco de as pessoas } \\
\text { simplesmente se cansarem. }\end{array}$ \\
\hline CWD & Utilize a técnica Crowdfunding para validar uma ideia. \\
\hline TRE & $\begin{array}{l}\text { Utilize a regra de três cliques do Steve Jobs e nunca deixe seus clientes estarem a mais de três } \\
\text { cliques de distância de seu produto. }\end{array}$ \\
\hline HIP & $\begin{array}{l}\text { Lembre-se de que todas as certezas na vida não passam de hipóteses até que se tornem fatos } \\
\text { (verificados). Seja um cientista tentando prová-las! Conduza pesquisas, testes para verificar } \\
\text { suas ideias e crenças. E se a validação der um resultado negativo, você deve comemorar! }\end{array}$ \\
\hline FMP & $\begin{array}{l}\text { "Feito é melhor do que perfeito", não perca tempo lapidando a beleza, e sim as } \\
\text { funcionalidades de seu produto. Crie o seu MVP e lance um "prótotipo de seu produto" para } \\
\text { receber feedbacks e realizar ajustes. }\end{array}$ \\
\hline $\mathrm{CCC}$ & $\begin{array}{l}\text { Converse com os clientes, experimente seu produto (analise com a visão do cliente), viva o } \\
\text { problema que deseja resolver. Se você não focar na experiência do cliente, estará perdendo } \\
\text { completamente o motivo do seu negócio. }\end{array}$ \\
\hline SPR & $\begin{array}{l}\text { Só porque seus clientes não estão dizendo que você está prestando um serviço ruim, não } \\
\text { significa que você não está prestando um serviço ruim. }\end{array}$ \\
\hline $\mathrm{NCC}$ & $\begin{array}{l}\text { Nunca é culpa do cliente, não fique na defensiva. Esteja programado para realizar, o mais } \\
\text { rápido possivel, melhoria ou ajuste. Somos humanos e vamos cometer erros, mas o cliente } \\
\text { lembrará mais sobre o quão rápido você corrigiu o erro do que do próprio erro em si. }\end{array}$ \\
\hline VSV & $\begin{array}{c}\text { Para ter sucesso, uma startup precisa se destacar em saber vender sua visão para outras } \\
\text { pessoas - pense em investidores, funcionários em potencial, clientes e parceiros. }\end{array}$ \\
\hline TEC & $\begin{array}{c}\text { Toda empresa de tecnologia precisa ter mais de um produto para ser duradoura. Se você é } \\
\text { uma empresa de tecnologia, não pode presumir que sua invenção é original e que você estará } \\
\text { vendendo daqui a muitos anos. }\end{array}$ \\
\hline $\mathrm{CHD}$ & $\begin{array}{l}\dot{E} \text { incrivelmente dificil quando tudo é importante e imediatamente necessário. Criar o hábito } \\
\text { constante de decidir o que é mais importante é poderoso. }\end{array}$ \\
\hline
\end{tabular}

Fonte: Autores

A partir desta lista, foi solicitado aos entrevistados que ordenassem as RS que consideravam mais importantes, conforme sua experiência. Como forma de obter as cinco RS prioritárias a partir da opinião dos cinco entrevistados, foi realizado um ranking, que consistiu no somatório de pesos, ou seja, a heurística considerada em primeiro lugar pelos entrevistados, obteve peso 5; em segundo lugar - peso 4; e assim por diante até quinto lugar - peso 1 . $\mathrm{O}$ resultado está representado na Figura 6. 
FIGURA 6 - Ranking das Regras Simples

\begin{tabular}{|c|c|c|c|c|c|c|}
\hline Código & Entrevistado 1 & Entrevistado 2 & Entrevistado 3 & Entrevistado 4 & Entrevistado 5 & Ranking \\
\hline $\mathrm{CCC}$ & $2^{\circ}$ & $3^{\circ}$ & $3^{\circ}$ & $2^{\circ}$ & $1^{\circ}$ & 19 \\
\hline VSV & $1^{\circ}$ & $1^{\circ}$ & $4^{\circ}$ & & $2^{\circ}$ & 16 \\
\hline $\mathrm{CHD}$ & $2^{\circ}$ & $2^{\circ}$ & $3^{\circ}$ & $4^{\circ}$ & & 13 \\
\hline HIP & & $5^{\circ}$ & $2^{\circ}$ & $1^{\circ}$ & $4^{\circ}$ & 12 \\
\hline FDC & & $4^{\circ}$ & $1^{\circ}$ & & $5^{\circ}$ & 8 \\
\hline FMP & & & $2^{\circ}$ & $3^{\circ}$ & & 7 \\
\hline NEC & $4^{\circ}$ & & & & $3^{\circ}$ & 5 \\
\hline SPR & & & & $5^{\circ}$ & & 1 \\
\hline TRE & $5^{\circ}$ & & & & & 1 \\
\hline \multicolumn{7}{|l|}{ CWD } \\
\hline \multicolumn{7}{|l|}{$\mathrm{NCC}$} \\
\hline TEC & & & & & & \\
\hline
\end{tabular}

Fonte: Autores

A partir das respostas, foi possível perceber a adaptação das RS a ambientes/situações específicas, reforçando a percepção dos entrevistados sobre o que a literatura denomina racionalidade ecológica (ou adaptação heurística-ambiente de decisão). Por exemplo, ao se deparar com FDC, $80 \%$ dos entrevistados reforçaram a necessidade de buscar diferenciais em termos de soluções para o que ainda não foi resolvido/não existe no mercado. Contudo, a maior parte dos entrevistados afirmou que é necessário avaliar quanto risco é possível suportar, dado que inovar e se diferenciar geralmente envolve arcar com custos maiores. Um entrevistado inclusive afirmou preferir pouca diferenciação/risco em seus negócios, buscando soluções de abrangência local com retorno de curto prazo. Outro exemplo é com relação a TRE, heurística apontada pelos entrevistados como um princípio essencial, contudo, de difícil execução. Alguns afirmaram que, em dadas situações, é muito difícil ou inviável implementar a regra de 3 cliques - seja pelo custo de design para chegar a tal nível de excelência, seja pela complexidade da tecnologia em termos de funções.

Quanto a VSV, houve concordância, e mesmo a sugestão, por um empreendedor, de que "na vida a gente não tem o que merece, tem o que negocia". Foi enfatizada a necessidade de "saber vender" internamente, dado o desafio de atrair bons recursos humanos no início do negócio.

Quanto a NEC, em geral, houve concordância entre os entrevistados. Contudo, dois dos entrevistados citam que "as pessoas não sabem o que querem", levando à necessidade de o empreendedor ofertar algo voltado aos desejos ou ao que não foi expresso. Tal observação pode indicar uma compreensão parcial ou mesmo limitação dos empreendedores em perceber a voz real do cliente. 
Com relação a HIP, entrevistados afirmaram que os testes não devem modificar a visão do negócio, mas suportar sua execução em constante aprendizagem sobre os clientes, evitando perdas de tempo e dinheiro. Entretanto, apesar de ser importante reconhecer quando uma ideia não é tão boa, dois pontos foram levantados como contrapontos a HIP: o desafio de convencer algum empreendedor que sua ideia/projeto não vale a pena e o desafio de saber até que ponto deve-se ouvir o cliente em termos da visão de negócio e até que ponto deve-se ouvir a própria paixão e/ou visão empreendedora: um equilíbrio delicado.

De modo aproximadamente análogo, a heurística CCC apresentou foi a de maior importância no ranking, envolvendo a utilização de "beta testers". Como benefícios foram listados, além dos benefícios de HIP, a possibilidade de crescimento equilibrado da demanda e capacidade de oferta; compreensão da verdadeira necessidade dos clientes - muitas vezes mais simples que a visão inicial; e auxílio ao empreendedor para acertar uma necessidade real. Entretanto, em alguns casos, acompanhar o cliente de perto foi visto como caro em termos de horas e de capital social, dado que nem sempre o cliente apresenta tal abertura em etapas iniciais da startup. Foi levantado também o risco da gestão de expectativas, dado que clientes muito próximos podem se sentir à vontade para solicitar um alto número de funcionalidades que divergem da estratégia da startup.

A heurística FMP apontou fatos concordantes, mas com ressalvas. Concordância que um MVP é importante, porém, dificuldades com o conceito e sua operação. Por exemplo, a percepção de que um "MVP robusto" pode ter uma execução demorada, postergando as validações e prejudicando o andamento do negócio. E, por outro lado, o receio de que "se for fazer uma entrega ruim é melhor não entregar", sendo necessário uma reflexão em cada caso.

No que tange a NCC, houve concordância com ressalvas. Por exemplo, citou-se o caso em que um cliente é um detrator do negócio ou cujas expectativas são percebidas como inatingíveis, o que pode levar à necessidade não de ouvi-lo, mas até mesmo "demitir o cliente". Também foi abordado que, em etapas iniciais, realmente o cliente terá maior tolerância a erros de correção rápida. Entretanto, em etapas finais de um projeto, o cliente pode não aceitar bem tal fato por se tornar mais exigente. Foi sugerido o uso de técnicas de priorização como meio de gestão de expectativa em cenários nos quais há mais solicitações do que capacidade imediata de solução.

Quanto a CHD houve concordância, com ênfase para a necessária habilidade de priorização. CWD, dada a amostra, mostrou que a técnica de Crowdfunding é pouco utilizada/conhecida. 
SPR foi vista como relevante, com considerações feitas sobre a necessidade (e eventual dificuldade) de criar canais de proximidade e sinceridade com clientes, que podem dizer sim apenas por educação ou mesmo apresentar critérios insuficientes para uma análise relevante.

Sobre TEC houve concordância predominante sobre a necessidade de diversificação, entretanto, apontamentos sobre a dificuldade de diversificar dado o risco de perder o foco e comprometer os escassos recursos para desenvolver uma solução em uma busca por desenvolver duas, em paralelo. Logo, foi dito sobre a necessidade de consolidar uma solução existente até reduzir riscos para engajar em diversificação.

\section{CONCLUSÃO}

Este trabalho obteve uma lista de heurísticas (RS) e, então, validou tais RS com empreendedores experientes em desenvolvimento de produtos digitais. Foi possível observar as RS como caminhos de apoio e orientação para a decisão e ação. Apesar de considerar uma amostra pequena de empreendedores entrevistados, eles demonstraram bom conhecimento das RS, indicando uma boa difusão de heurísticas na prática do empreendedorismo digital.

Também foram enfatizados aspectos da racionalidade ecológica de heurísticas, em prevenção às abordagens one-size-fits-all: de modo simples, uma análise caso-a-caso da aderência de RS. Os empreendedores corroboraram tal aspecto ao responder que, embora concordassem e mesmo relatassem já ter utilizado a maioria das RS, percebiam que em alguns cenários seu uso deveria considerar ressalvas, sendo as ressalvas principais expostas neste artigo.

Este estudo reforçou também o caráter aplicado de heurísticas enquanto princípios de design capazes de orientar a decisão e ação em ambientes de incerteza/mudança. Tanto pela fonte de dados, isto é, livros da chamada "literatura cinzenta" que traziam casos de empreendedores e startups digitais quanto pelo escrutínio dos empreendedores. Estes relataram conhecimento, concordância com a RS e uso comprovado com exemplos reais para mais de $80 \%$ das heurísticas contidas na lista final. Diferenças na experiência, idade e formação dos empreendedores não interferiram neste aspecto, reforçando-o.

Contudo, deve-se notar que este estudo dispôs de uma perspectiva indutiva exploratória orientada ao avanço de conhecimento na área mais do que à proposição de teorias de ampla cobertura. Aspecto não percebido como uma fraqueza, e sim uma escolha metodológica que propõe temas para análise de estudos futuros que utilizem metodologias de natureza 
dedutiva/descritiva a fim de verificar se os achados são de fato representativos para a área de desenvolvimento de produtos no contexto do empreendedorismo digital.

\section{REFERÊNCIAS}

ARTINGER, F. et al. Heuristics as adaptive decision strategies in management. Journal of Organizational Behavior, v. 36, n. S1, p. S33-S52, fev. 2015.

BHARGAVA, R.; HERMAN, W. The Startup Playbook: Founder-to-Founder Advice from Two Startup Veterans. New Jersey: Wiley, 2020.

BETTIS, R. A. Organizationally Intractable Decision Problems and the Intellectual Virtues of Heuristics. Journal of Management, v. 43, n. 8, p. 2620-2637, nov. 2017.

BINGHAM, C.; EISENHARDT, K. Rational heuristics: the 'simple rules' that strategists learn from process experience. Strategic Management Journal, v. 32, n. 13, p. 1437-1464, dez. 2011.

BLANK, S.; DORF, B. The startup owner's manual: the step-by-step guide for building a great company. Pescadero, Calif.: K \& S Ranch, 2012.

DAVIS, J. ; EISENHARDT, K.; BINGHAM, C. Optimal Structure, Market Dynamism, and the Strategy of Simple Rules. Administrative Science Quarterly, v. 54, n. 3, p. 413-452, set. 2009.

FRANCO, L.; ROUWETTE, E. Decision development in facilitated modelling workshops. European Journal of Operational Research, v. 212, n. 1, p. 164-178, jul. 2011.

GALLAGHER, L. The Airbnb story: How three ordinary guys disrupted an industry, made billions... and created plenty of controversy. [s.l.] Mariner Books, 2017. v. eBook Kindle.

GIOIA, D.; CORLEY, K.; HAMILTON, A. Seeking qualitative rigor in inductive research: Notes on the Gioia methodology. Organizational research methods, v. 16, n. 1, p. 15-31, 2013.

GOMES, T. Nada Easy: O passo a passo de como combinei gestão, inovação e criatividade para levar minha empresa a 35 países em 4 anos. 2. ed. São Paulo: Gente, 2017. v. eBook Kindle.

GREEN, B. All in: 101 real life business lessons for emerging entrepreneurs. Delaware: Eagle Creek, 2017. v. eBook Kindle.

GRIFFIN, D.; GONZALEZ, R.; KOHELER, D.; GILOVICH, T. Judgmental Heuristics: A historical Overview. In: HOLYOAK, K.; MORRISON, R. (Eds.). The Oxford handbook of thinking and reasoning. Oxford University Press, 2013.

HULL, C. et al. Taking advantage of digital opportunities: a typology of digital entrepreneurship. International Journal of Networking and Virtual Organisations, v. 4, n. 3, p. 290-303, 2007.

KING, N.; BROOKS, J. Thematic Analysis in Organisational Research. In: CASSELL, C.; CUNLIFFE, A.; GRANDY, G. (Eds.). . The SAGE handbook of qualitative business and management research methods. Thousand Oaks, CA: SAGE Publications, 2017. p. 219-236.

LUAN, S.; REB, J.; and GIGERENZER, G. Ecological rationality: Fast-and-frugal heuristics for managerial decision making under uncertainty. Academy of Management Journal. 2019.

MANIMALA, M. J. Entrepreneurial Heuristics: A comparison between high PI (Pioneering-Innovative) and low PI ventures. Journal of Business Venturing, v. 7, n. 6, p. 477-504, 1992.

MAKINGS, A.; BARNARD, B. The Heuristics of Entrepreneurs. SSRN Electronic Journal, 2019.

O'CONNOR, C.; JOFFE, H. Intercoder reliability in qualitative research: debates and practical guidelines. International Journal of Qualitative Methods, v. 19, 2020.

RATINHO, T.; HARMS, R.; WALSH, S. Structuring the Technology Entrepreneurship publication landscape: Making sense out of chaos. Technological forecasting and social change, v. 100, p. 168-175, 2015.

RIES, E. The Lean Startup: How Today's Entrepreneurs Use Continuous Innovation to Create Radically Successful Businesses. [s.l.] Crown Business, 2011. 
SALERNO, M. et al. Innovation processes: Which process for which project? Technovation, v. 35, p. 59-70, jan. 2015.

SIMON, H. A behavioral model of rational choice. The quarterly journal of economics, v. 69, n. 1, p. 99-118, 1955.

SIMON, H. Models of bounded rationality. vol. 2, Behavioral economics and business organization. MIT Press, 1982.

SOUZA, M.; MELO FILHO, L.; CHENG, L. P-Start: Processo Para Geração de Startups e Kit De Ferramentas. In: BAGNO, R.; SOUZA, M.; CHENG, L. (Eds.). . Perspectivas sobre o empreendedorismo tecnológico: Da ação empreendedora aos programas de apoio e dinâmica do ecossistema. Curitiba: Brazil Publishing, 2020. p. 111-160.

STINGL, V.; GERALDI, J. A research agenda for studying project decision-behaviour through the lenses of simple heuristics. Technological Forecasting and Social Change, v. 162, p. 120367, 2021.

SULL, D.; EISENHARDT, K. M. Simple rules for a complex world. Harvard Business Review, v. 90, n. 9, p. 68-76, 2012.

SULL, D. N.; EISENHARDT, K. M. Simple rules: how to thrive in a complex world. Boston: Houghton Mifflin Harcourt, 2015.

TVERSKY, A.; KAHNEMAN, D. Judgment under uncertainty: Heuristics and biases. Science, v. 185, n. 4157, p. 1124-1131, 1974.

WENZEL, M.; STJERNE, I. Heuristics-in-use: Toward a practice theory of organizational heuristics. Technological Forecasting and Social Change, v. 164, p. 120517, 2021

WEST, D.; ACAR, O.; CARUANA, A. Choosing among alternative new product development projects: The role of heuristics. Psychology \& Marketing, v. 37, n. 11, p. 1511-1524, 2020.

ZAHEER, H.; BREYER, Y.; DUMAY, J. Digital entrepreneurship: An interdisciplinary structured literature review and research agenda. Technological Forecasting and Social Change, v. 148, p. 119735, 2019.

ZHANG, S.; CUETO, J. The study of bias in entrepreneurship. Entrepreneurship theory and Practice, v. 41, n. 3, p. 419-454, 2017. 